\title{
THE EFFECT OF FEEDING PROBLEMS ON THE GROWTH OF CHILDREN AND ADOLESCENTS WITH CEREBRAL PALSY
}

\author{
R. Rajikan ${ }^{1,2}$, N. M. Zakaria ${ }^{1,2}$, Z. A. Manaf ${ }^{1,2}$, N. A. M. Yusoff ${ }^{3,4, *}$ and S. Shahar ${ }^{1,2}$ \\ ${ }^{1}$ Dietetic Science Program, School of Health Care Sciences, Faculty of Health Sciences, \\ UniversitiKebangsaan Malaysia, 50300 Kuala Lumpur, Malaysia \\ ${ }^{2}$ Community Rehabilitation and Ageing Research Center, Faculty of Health Sciences, \\ UniversitiKebangsaan Malaysia, 50300 Kuala Lumpur, Malaysia \\ ${ }^{3}$ School of Nutrition and Dietetics, Faculty of Health Sciences, Universiti Sultan ZainalAbidin, \\ 21300 Kuala Nerus, Terengganu, Malaysia \\ ${ }^{4}$ Institute for Community (Health) Development, Universiti Sultan ZainalAbidin, 21300 Kuala \\ Nerus, Terengganu Malaysia
}

Published online: 10 November 2017

\begin{abstract}
This cross sectional study determine the growth, feeding problems and nutrient intakes of cerebral palsy children and adolescents. A total of 153 subjects (68 females, 85 males) aged between 2 to 15 years old (mean $8.93 \pm 3.5$ ) from community rehabilitation centers and spastic centers around Kuala Lumpur, Muar and Penang were recruited using convenience sampling method. $61 \%$ of subjects had feeding problems especially in the severe level group $(72.9 \%)$ as compared to the mild $(50.6 \%)\left[\left(\chi^{2}=7.890\right), \mathrm{p}<0.05\right]$, whereby choking and swallowing were significantly associated with their severity levels $\left[\left(\chi_{\text {choking }}^{2}=7.183\right), \mathrm{p}<0.05 ;\left(\chi_{\text {swallowing }}^{2}=9.994\right)\right.$, $\mathrm{p}<0.05]$. Subjects with feeding problems have lower body weight, height, BMI, triceps skin fold and MUAC ( $\mathrm{p}<0.05$ for all parameters).
\end{abstract}

Author Correspondence, e-mail: noorainimy@unisza.edu.my

doi: http://dx.doi.org/10.4314/jfas.v9i6s.59 
$60 \%$ of cerebral palsy subjects had poor nutritional status, feeding problems and the presence of feeding problems significantly affects their growth.

Keywords: cerebral palsy; feeding problem; specific growth charts; gross motor classification system; wasting.

\section{INTRODUCTION}

Cerebral palsy is a neurodevelopment disorder that is acquired during childhood, which affects their motor system causing limitations in their daily activities with the birth rate of 2.0 to 2.5 in every 1000 births [1-2]. The growth rate amongst cerebral palsy is affected by their level of severity dietary intake and feeding problems [3-5].However, as their age increases, a better linear growth is observed, due to better gross motor skills, food intake and overall health status [6].

Despite their difference in body posture, these children are generally smaller and thinner compared to normal children, especially amongst the quadriplegics [6-7]. The incidence of stunting and wasting are more prevalent in the more severe groups [4]. However, researchers are still comparing the growth of cerebral palsy children with growth charts for normal developing children. Thus, in order to understand the growth pattern of the CP children and adolescents, comparisons should be made with specific growth charts [8].

Feeding problem which are common among the cerebral palsy population were able to affect the children growth [9]. Inability to communicate their hunger and satiety causes their caretakers to uptake the responsibility in monitoring their diet [10]. Besides, severe feeding problems causing lower food consumption were also associated with poor nutritional status [11]. Feeding these children who are prone to aspiration and prolonged mealtimes, feeding tubes is strongly recommended [10]. Feeding tubes would be able to help these children get the proper nutrients, which eventually will be able to improve their weight status $[5,9]$.

Issues regarding growth and feeding problems amongst cerebral palsy children and adolescents are still unsolved due the paucity of research in this area of study, especially in Malaysia. Hence, the aim of this cross sectional study was to determine the influence of feeding problems on the growth of children and adolescents with cerebral palsy. The present study shows the effect of feeding problems faced by subjects on their nutritional status and 
dietary intakes, which could aid in constructing suitable intervention and treatment programmes to improve their growth. More subjects from the severe group were predicted to face feeding problems and have poorer nutritional status compared to the mild group subjects.

\section{METHODOLOGY}

\subsection{Participants}

This cross sectional study was conducted amongst 153 cerebral palsy children aged between 2 and 15 years old from selected Spastic Centres and Community Rehabilitation Centres around Kuala Lumpur, Muar and Penang area through convenience sampling method. In this study, subjects were chosen based on the cerebral palsy definition [1]. They defined cerebral palsy as a group of disorder of the development of movement and posture, causing activity limitation, that are attributed to non-progressive disturbances that occurred in the developing fetal or infant brain. Subjects were classified according to their gross motor skills based on the Gross Motor Function Classification System (GMFCS) [12]. However, due to the imbalance in number of subjects in certain groups, subjects were further grouped into 2 groups namely mild (GMFCS I, II, III and IV) and severe (GMFCS V). Subjects which acquired cerebral palsy through postnatal origin (near drowning incidents, motor vehicle accidents) and patients with significant associated diagnosis (autism, down syndrome) were excluded. Ethical approval was obtained from UniversitiKebangsaan Malaysia Research Ethical Committee PPUKM and informed consent was obtained from parents or legal guardian of each subjects.

\subsection{Anthropometric Measurements}

Anthropometry measurements were conducted by measuring body weight, knee height, mid upper arm circumference (MUAC) and triceps skin fold thickness. Duplicate measurements were obtained and the average measurement used for analyses. Weight was measured using TANITA digital weighing scale to the nearest $0.01 \mathrm{~kg}$. Subjects who were unable to stand, weight was measured together with their parent which then was subtracted with the caregiver's weight. Measuring actual height amongst cerebral palsy is difficult due to the presence of contractures and their inability to stand [13]. Thus, height was measured using knee height calipers and estimated with Stevenson's Equation to the nearest $0.1 \mathrm{~cm}$. Subjects' triceps skin fold was measured using Harpendencalipers to the nearest $0.1 \mathrm{~mm}$ [14]. MUAC 
was measured using non elastic SECA measuring tape to the nearest $0.1 \mathrm{~cm}$ respectively. Body mass index (BMI) was calculated using the following formula: weight $(\mathrm{kg}) / \mathrm{height}\left(\mathrm{m}^{2}\right)$. Weight, height and BMI measurements were compared to both growth charts for cerebral palsy whilst skin fold and MUAC measurements were compared [15-16].

\subsection{Feeding Problems}

Feeding problems amongst the cerebral palsy subjects were assessed using the Parent Nutrition Screening Checklist questionnaire [17]. The questionnaire comprised of 18 questions, which include subjects general health, feeding problems, behavior problems and dietary habits based on the parents perception. However, the present study only focussed on the presence and type of feeding problems experienced by the subject [30].

\subsection{Nutritional Intake}

Parents or guardian were informed to record their child's food intake for three consecutive days (two weekdays and one weekend) in the food diary provided. Their mean daily energy and macronutrient intake were calculated using the Nutritionist Pro v 3.10 software. Energy intakes of subjects were compared to their energy needs based recommendation which were adjusted for their age, gender and level of physical activity [18]. The macronutrient and micronutrient intakes were compared to the Malaysia's Recommended Nutrient Intake (RNI) 2005 distribution values based on sex and age [19].

\subsection{Data Analyses}

Socio demographic data, nutritional status distribution and types of feeding problems experienced by subjects were analyzed descriptively and expressed as frequencies and percentages. Nonparametric test were chosen prior to the disagreement of the normality test, Shapiro-Wilk conducted. Differences in mean anthropometric measurements, energy and nutrient intakes between mild and severe groups were compared using Mann Whitney U Test. Difference in nutritional status between subjects with and without feeding problems were also compared using Mann Whitney U Test. The association between presence of feeding problems and the severity groups were tested using chi square test. The significance level for all statistical tests was set at $\mathrm{p}<0.05$. Data were analyzed using SPSS version 16 statistical software. 


\section{RESULTS AND DISCUSSION}

A total of 153 out of 186 children and adolescents with cerebral palsy had returned their questionnaires (82.3\% response rate) whilst 130 subjects had returned their food diaries. Weight and height measurements managed to be assessed in 126 subjects, whilst triceps skin fold measurements and MUAC were managed to be measured in 113 subjects and 109 subjects respectively. A total of 153 cerebral palsy subjects ( 85 males, 68 females) with the mean age of $8.93 \pm 3.5$ years old, with more than half of the subjects were mildly disabled (54.2\%) participated in the study. Majority of the subjects were Malay (69\%) followed by Chinese (23.9\%) and Indian (4.5\%) from CRC and Spastic Centre around Penang (48.4\%), Kuala Lumpur (35.9\%) and Muar (15.7\%) area (Table 1). 
Table 1.Demographic characteristics of children and adolescent with cerebral palsy

\begin{tabular}{|c|c|c|}
\hline & $\mathbf{n}$ & $\%$ \\
\hline \multicolumn{3}{|l|}{ Gender } \\
\hline Male & 85 & 55.6 \\
\hline Female & 68 & 44.4 \\
\hline \multicolumn{3}{|l|}{ Age Range (years) } \\
\hline $1-6$ & 49 & 32.0 \\
\hline $7-12$ & 83 & 54.2 \\
\hline $12-15$ & 21 & 13.7 \\
\hline \multicolumn{3}{|l|}{ Ethnic } \\
\hline Malay & 107 & 69.0 \\
\hline Chinese & 37 & 23.9 \\
\hline Indian & 7 & 4.5 \\
\hline Eurasian & 2 & 1.3 \\
\hline \multicolumn{3}{|l|}{ State } \\
\hline Kuala Lumpur & 55 & 35.9 \\
\hline Penang & 74 & 48.4 \\
\hline Muar, Johor & 24 & 15.7 \\
\hline \multicolumn{3}{|l|}{ Level of Severity } \\
\hline Mild $^{\mathrm{a}}$ (GMFCS I, II, III and IV) & 83 & 54.2 \\
\hline Severe $^{\mathrm{b}}(\mathrm{GMFCS} \mathrm{V})$ & 70 & 45.8 \\
\hline
\end{tabular}

${ }^{\mathrm{a}}$ Mild = GMFCS Level I, II, III and IV

${ }^{\mathrm{b}}$ Severe $=$ GMFCS V

The severe group subjects had significantly lower weight (severe $18.8 \pm 12.5$ versus mild 23.0+11.9), height (severe 112. $0+17.5$ versus mild 121.4+16.9) and mid upper arm circumference (severe 18.6+4.0 versus mild $21.1+5.4)$ compared with the mild group $(\mathrm{p}<$ 0.05). Although more than half of the subjects had normal weight $(>5$ th percentile to $<95$ th percentile) $(75.4 \%)$, a third of the subjects were found to be underweight (BMI lower than 5th percentile) (29.5\%) with triceps skin fold (36.2\%) and MUAC (25.5\%) lower than the 5th percentile (Table 2). 
Table 2. Distributions of nutritional status of subjects based on specific growth chart and reference [15-16]

\begin{tabular}{|c|c|c|c|}
\hline & Mild Level, n (\%) & Severe Level, n (\%) & Total, n (\%) \\
\hline \multicolumn{4}{|c|}{ Weight-for-age $^{\mathrm{a}}$} \\
\hline$<5$ th percentile & $9(14.8 \%)$ & $9(13.8 \%)$ & $18(14.9 \%)$ \\
\hline$>5$ th percentile- $<95$ th percentile & $46(75.4 \%)$ & $52(80.0 \%)$ & $98(77.8 \%)$ \\
\hline \multirow[t]{2}{*}{$>95$ th percentile } & $6(9.8 \%)$ & $4(6.2 \%)$ & $10(7.9 \%)$ \\
\hline & Height-for-age $^{a}$ & & \\
\hline$<5$ th percentile & - & - & - \\
\hline$>5$ th percentile- $<95$ th percentile & $59(96.7 \%)$ & $64(98.5 \%)$ & $123(97.6 \%)$ \\
\hline \multirow[t]{2}{*}{$>95$ th percentile } & $2(3.3 \%)$ & $1(1.5 \%)$ & $3(2.4 \%)$ \\
\hline & BMI-for-age $^{a}$ & & \\
\hline$<5$ th percentile & $18(29.5 \%)$ & $24(36.9 \%)$ & $42(33.3 \%)$ \\
\hline$>5$ th percentile- $<95$ th percentile & $41(67.2 \%)$ & $39(60.0 \%)$ & $80(63.5 \%)$ \\
\hline \multirow[t]{2}{*}{$>95$ th percentile } & $2(3.3 \%)$ & $2(3.1 \%)$ & $4(3.2 \%)$ \\
\hline & MUAC-for-age ${ }^{b}$ & & \\
\hline$<5$ th percentile & $14(25.5 \%)$ & $18(33.3 \%)$ & $32(29.4 \%)$ \\
\hline$>5$ th percentile- $<95$ th percentile & $31(56.4 \%)$ & $29(53.7 \%)$ & $60(55.0 \%)$ \\
\hline \multirow[t]{2}{*}{$>95$ th percentile } & $10(18.2 \%)$ & $7(13.0 \%)$ & $17(15.6 \%)$ \\
\hline & Triceps-for-age ${ }^{b}$ & & \\
\hline$<5$ th percentile & $21(36.2 \%)$ & $17(30.9 \%)$ & $38(33.6 \%)$ \\
\hline$>5$ th percentile- $<95$ th percentile & $33(56.9 \%)$ & $34(61.8 \%)$ & $67(59.3 \%)$ \\
\hline$>95$ th percentile & $4(6.9 \%)$ & $4(7.3 \%)$ & $8(7.1 \%)$ \\
\hline
\end{tabular}

${ }^{\mathrm{a}}$ These indicators were referred to [15] specific growth chart

${ }^{\mathrm{b}}$ These indicators were referred to [16] reference A total of 93 subjects had feeding problems, whereby significantly more subjects from the severe group were noticed to experienced feeding problems compared to the mild group subjects $\left[\chi^{2}(1)=7.890, p<0.05\right]$. Choking (15.5\%) and swallowing problems (20.2\%) were found to be associated with subjects severity level $\left[\chi_{\text {choking }}^{2}(1)=7.183, \mathrm{p}<0.05 ; \chi_{\text {swallowing }}^{2}(1)=9.994, \mathrm{p}<0.05\right]$ (Table 3 ). However, subjects with feeding problem were found to have significantly lower BMI 
$(13.5 \pm 4.4$ vs $15.9 \pm 5.5, \mathrm{z}=-2.343, \mathrm{p}<0.05)$ and MUAC $(18.7 \pm 4.1$ vs $22.0 \pm 5.4, \mathrm{z}=-3.318, \mathrm{p}<$ 0.001) compared to the mild group subjects (Table 4).

Table 3. Nutritional status between presences of feeding problems faced by subjects

\begin{tabular}{cccccc}
\hline & n ( \%) & Mild Level & Severe Level & $\boldsymbol{\chi}^{\mathbf{2} \text { Value }}$ & P-Value \\
\hline $\begin{array}{c}\text { Presence of } \\
\text { Feeding Problems }\end{array}$ & 153 & 83 & 70 & & \\
Yes & $93(60.8)$ & $42(27.5)$ & $51(33.3)$ & 7.890 & $0.005^{\mathrm{a}}$ \\
No & $60(39.2)$ & $41(26.8)$ & $19(12.4)$ & & \\
Types of feeding problem & & & & & \\
Sucking & $46(19.3)$ & $21(45.6 \%)$ & $25(54.4 \%)$ & 1.958 & $0.215^{\mathrm{a}}$ \\
Choking/spluttering & $37(15.5)$ & $13(35.1 \%)$ & $24(64.9 \%)$ & 7.183 & $0.008^{\mathrm{a}}$ \\
Sensitive around & $9(3.8)$ & $6(57.1 \%)$ & $3(42.9 \%)$ & 0.594 & $0.509^{\mathrm{b}}$ \\
the mouth area & & & & & \\
Chewing & $69(29.0)$ & $33(47.8 \%)$ & $36(52.2 \%)$ & 2.089 & $0.192^{\mathrm{a}}$ \\
Regurgitation & $29(12.2)$ & $15(51.7 \%)$ & $14(48.3 \%)$ & 0.092 & $0.837^{\mathrm{a}}$ \\
Swallowing & $48(20.2)$ & $17(35.4 \%)$ & $31(64.6 \%)$ & 9.994 & $0.003^{\mathrm{a}}$ \\
\hline
\end{tabular}

${ }^{\mathrm{a}}$ Significant difference $(\mathrm{p}<0.05)$ based on Mann Whitney U test

${ }^{\mathrm{b}} \mathrm{BMI}=$ Body Mass Index

${ }^{\mathrm{c}} \mathrm{MUAC}=$ Mid Upper Arm Circumference

Table 4. Feeding problems between different levels of severity amongst subjects

\begin{tabular}{cccc}
\hline & \multicolumn{2}{c}{ Presence of Feeding Problems } & P-Value $^{\mathrm{a}}$ \\
& Yes & No & \\
\hline BMI $^{\mathrm{b}}\left(\mathrm{kg} / \mathrm{m}^{2}\right)$ & $13.5 \pm 4.4$ & $15.9 \pm 5.5$ & 0.019 \\
Triceps Skin Fold $(\mathrm{mm})$ & $12.0 \pm 10.5$ & $14.6 \pm 10.2$ & 0.132 \\
$\operatorname{MUAC}^{\mathrm{c}}(\mathrm{mm})$ & $18.7 \pm 4.1$ & $22.0 \pm 5.4$ & 0.001 \\
\hline
\end{tabular}

${ }^{a}$ Significant association $(\mathrm{p}<0.05)$ based on Chi Square assumption test

${ }^{\mathrm{b}}$ Significant association $(\mathrm{p}<0.05)$ based on Fisher Exact TestEnergy intake in both groups was adequate $(\mathrm{RNI}>100 \%)$, with intakes higher amongst the mild group (1649 kcal/day) compared to the severe group (1449 kcal/day) (Table 5). The percentage of contributions of the macronutrients to total energy intake was similar by severity. The mild cerebral palsy 
group comprised of higher protein (mild 16.4\% versus severe 15.9\%) and fat (mild 31.4\% versus severe $30.2 \%$ ) with lower carbohydrate (mild 51.2\% and 52.5\% severe) compared to the severe group. Besides, the distributions of macronutrient were in accordance with the Malaysian RNI recommendation except protein which were higher. Overall, the intakes of the micronutrients were higher than their recommended intake levels. However, the intakes of Thiamine (mild 148\% versus severe 131\%) and fiber (mild 26\% versus severe $20 \%$ ) were significantly higher amongst the mild group compared to the severe subjects group $(\mathrm{p}<0.05)$.

\section{CONCLUSION}

The present study found that the majority children and adolescents with cerebral palsy appeared to be growing adequately. However, it is a concern that one third of the subjects were found to be underweight. Another study conducted among CP children in Malaysia had reported a higher prevalence of underweight (80\%) probably due to the study was carried out at tertiary health centers, of which health problems were more prominent. In [20] who had conducted a retrospective clinic-based study in Michigan had also reported higher incidence of underweight cases amongst subjects from GMFCS IV and V (40\%). Both these studies had compared the growth of their cerebral palsy subjects with the growth chart for normal population which may exaggerate the growth retardation amongst the cerebral palsy population [7]. The usage of specific growth charts would be more accurate to monitor the growth of cerebral palsy subjects as these growth charts takes into account the difference in their severity levels $[3,15]$. Nevertheless, taking into account that cerebral palsy is a heterogeneous condition; the use of cerebral palsy growth chart might not represent the ideal weight and height for this population [3]. On the contrary, these charts just serve as reference of how a certain cerebral palsy population grow [21].

The present study revealed, almost one third of the subjects have low triceps skin fold-for-age (36.2\%). The median triceps skin fold were lower amongst the severe group subjects compared to the mild group which is similar to the findings reported by previous study [13]. They found that patients attending the pediatric clinic in Egypt with cerebral palsy from GMFCS III to $\mathrm{V}$ had lower triceps skin fold measurements compared to patients from GMFCS I and II, which indicates that the severe group has lower fat stores. However, triceps 
skin fold and MUAC method being used in the present study to determine the fat stores amongst cerebral palsy subjects may be inaccurate as muscle wasting is generally evident among these subjects especially on their affected limbs [22-23].

Table 5. Energy and nutrient intakes amongst severe cerebral palsy subjects

\begin{tabular}{|c|c|c|c|c|c|c|c|}
\hline $\begin{array}{c}\text { Meal } \\
\text { s }\end{array}$ & $\begin{array}{c}\text { Day } \\
1\end{array}$ & Day 2 & Day 3 & Day 4 & Day 5 & Day 6 & Day 7 \\
\hline $\begin{array}{c}\text { Break } \\
\text { fast }\end{array}$ & $\begin{array}{c}\text { Fried } \\
, \\
\text { noodl } \\
\text { es } \\
\text { Tea }\end{array}$ & $\begin{array}{c}\text { 'Kam } \\
\text { pong' } \\
\text { Fried } \\
\text { rice } \\
\text { Tea }\end{array}$ & $\begin{array}{c}\text { 'Kam } \\
\text { pong' } \\
\text { Fried } \\
\text { rice } \\
\text { Tea } \\
\text { with } \\
\text { low-fa } \\
\text { t milk } \\
\text { Banan } \\
\text { a }\end{array}$ & $\begin{array}{c}\text { Noodle, soup } \\
\text { Tea }\end{array}$ & $\begin{array}{c}\text { Pancak, } \\
\text { wheat } \\
\text { Tea }\end{array}$ & $\begin{array}{c}2 \text { pieces } \\
\text { white } \\
\text { bread } \\
1 / 4 \\
\text { teaspoon } \\
\text { of } \\
\text { margarine } \\
1 \text { glass of } \\
\text { low-fat } \\
\text { milk }\end{array}$ & $\begin{array}{c}\text { Fried, } \\
\text { noodles } \\
\text { Tea }\end{array}$ \\
\hline $\begin{array}{l}\text { Morn } \\
\text { ing } \\
\text { tea }\end{array}$ & $\begin{array}{c}2 \\
\text { piece } \\
\text { s of } \\
\text { sardi } \\
\text { ne } \\
\text { bun } \\
\text { Tea }\end{array}$ & $\begin{array}{c}2 \\
\text { pieces } \\
\text { of } \\
\text { sardin } \\
\text { e } \\
\text { sandw } \\
\text { ich } \\
\text { Tea } \\
\text { with } \\
\text { low-fa } \\
\text { t milk }\end{array}$ & $\begin{array}{c}1 \\
\text { glass } \\
\text { of full } \\
\text { cream } \\
\text { milk }\end{array}$ & $\begin{array}{l}6 \text { pieces } \\
\text { cekodokpisang } \\
\text { Tea with low-fat } \\
\text { milk }\end{array}$ & $\begin{array}{c}2 \text { pieces } \\
\text { toasted } \\
\text { bread } \\
1 \text { glass of } \\
\text { low-fat } \\
\text { milk }\end{array}$ & $\begin{array}{c}\text { Pancake, } \\
\text { wheat } \\
\text { Tea }\end{array}$ & $\begin{array}{c}2 \text { pieces } \\
\text { of toasted } \\
\text { bread } \\
1 \text { glass of } \\
\text { low-fat } \\
\text { milk }\end{array}$ \\
\hline $\begin{array}{c}\text { Lunc } \\
\mathrm{h}\end{array}$ & $\begin{array}{l}\text { Cook } \\
\text { ed, } \\
\text { rice } \\
\text { Sardi }\end{array}$ & $\begin{array}{l}\text { Cooke } \\
\text { d, rice } \\
\text { Sardin } \\
\text { e, }\end{array}$ & $\begin{array}{l}\text { Cooke } \\
\mathrm{d} \text {, rice } \\
\text { Indian } \\
\text { macke }\end{array}$ & $\begin{array}{l}\text { Cooked, rice } \\
\text { Ikankembongkecil } \\
\text { masaksinggang } \\
\text { String bean, fried }\end{array}$ & $\begin{array}{l}\text { Cooked, } \\
\text { rice } \\
\text { Catfish, } \\
\text { cooked in }\end{array}$ & $\begin{array}{l}\text { Cooked, } \\
\text { rice } \\
\text { Hairtailsca } \\
\text { d, fried in }\end{array}$ & $\begin{array}{l}\text { Cooked, } \\
\text { rice } \\
\text { Hairtailsc } \\
\text { ad, fried }\end{array}$ \\
\hline
\end{tabular}




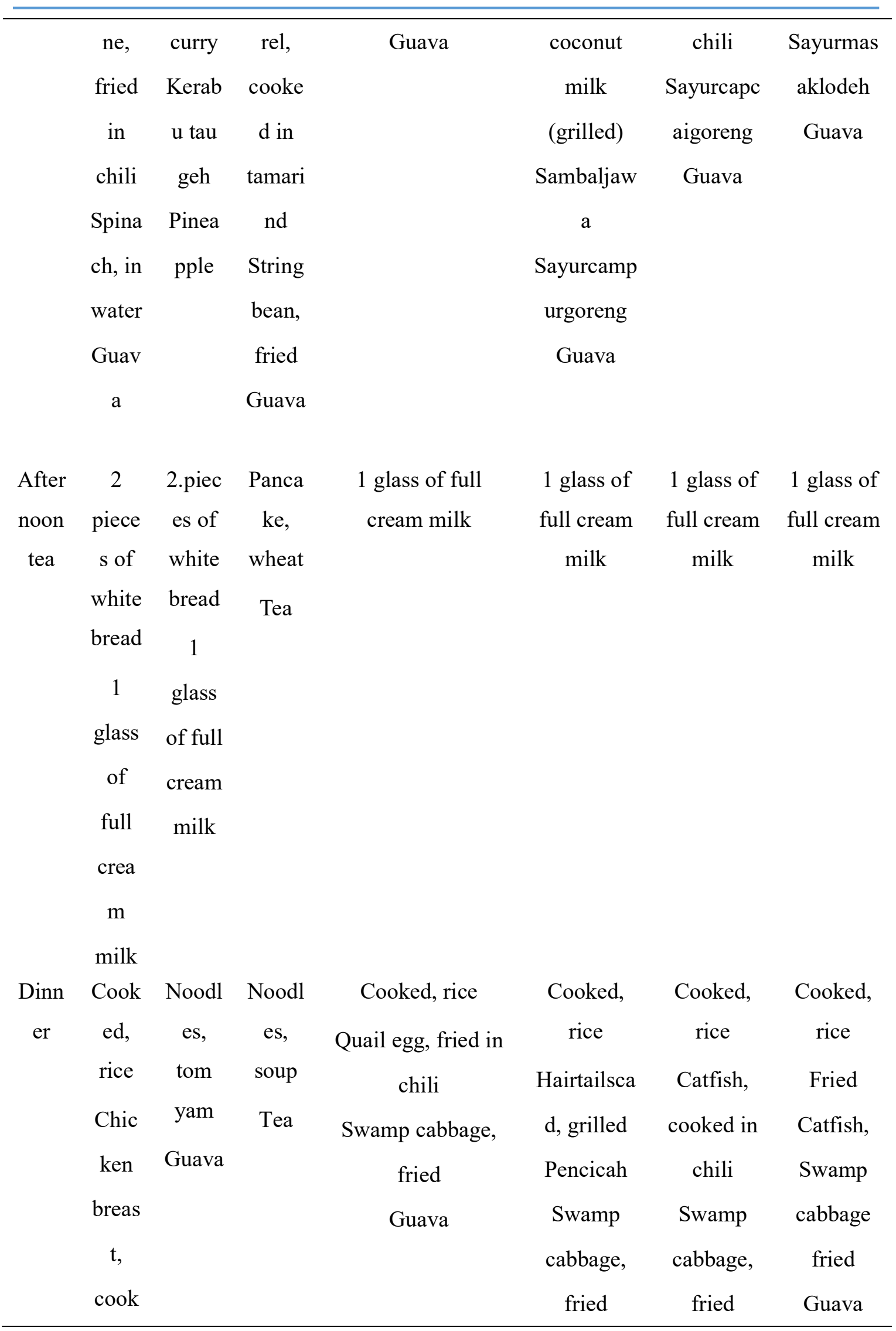




\begin{tabular}{|c|c|c|c|c|c|c|c|}
\hline & ed in & & & & Guava & Guava & \\
\hline & soy & & & & & & \\
\hline & sauce & & & & & & \\
\hline & Egg & & & & & & \\
\hline & Bean & & & & & & \\
\hline & sprou & & & & & & \\
\hline & ts & & & & & & \\
\hline & with & & & & & & \\
\hline & tofu, & & & & & & \\
\hline & cook & & & & & & \\
\hline & ed in & & & & & & \\
\hline & coco & & & & & & \\
\hline & nut & & & & & & \\
\hline & milk & & & & & & \\
\hline & Pinea & & & & & & \\
\hline & pple & & & & & & \\
\hline Food & 6.55 & 6.55 & 8.91 & 8.91 & 10.44 & 10.44 & 10.44 \\
\hline cost & & & & & & & \\
\hline per & & & & & & & \\
\hline day & & & & & & & \\
\hline$(\mathrm{RM})$ & & & & & & & \\
\hline Meal & Day & Day 2 & Day 3 & Day 4 & Day 5 & Day 6 & Day 7 \\
\hline $\mathrm{S}$ & 1 & & & & & & \\
\hline
\end{tabular}

Percentage of achievement based on recommendation

${ }^{\mathrm{b}} \mathrm{EI}=$ Energy intake $(\mathrm{kcal})$

${ }^{c} \mathrm{EER}=$ Estimated Energy Intake

${ }^{\mathrm{d}}$ Compared to the recommendation made by previous study [18]

${ }^{\mathrm{e}}$ Compared to the recommendation of Recommended Nutrient Intake (RNI)

${ }^{\mathrm{f}}$ Significant difference $(\mathrm{p}<0.05)$ based on Mann Whitney U test

${ }^{\mathrm{g}}$ Number of subjects achieving lower than $100 \%$ of the recommended levels 
Majority of the subjects' caloric intake was adequate with higher energy intake to expenditure being reported especially amongst the severe group. This finding is similar to a previous study comparing the energy intakes between cerebral palsy subjects and their siblings, whereby the caloric intakes amongst the disabled subjects were inadequate [4]. Higher ratio of energy intake to expenditure amongst the severely participants were also reported, which could be possible due to the parents higher tendency to overestimate their child's food intake especially amongst the severe subjects. This happens when parents were not able to measure and report the amount of food wastes during meal time due to feeding problems often experienced by cerebral palsy subjects [24]. Besides, higher ratio of energy intake to expenditure could also be influenced by their low physical activity which is due to their disability.

Fiber intakes amongst subjects of the present study was very poor $(24 \%)$, lower than the recommended levels with significantly lower intakes amongst the severe subjects (20\%) compared to subjects with mild severity $(\mathrm{z}=-2.361, \mathrm{p}<0.05)$. This happens due to subjects' poor ability to chew vegetables and fruits, causing parents to feed these children with smaller vegetables and fruit portions. Similar findings were also reported in a study determining the prevalence of constipation amongst individuals from GMFCS IV and V in Netherlands, whereby their daily fiber intakes were lower than their required standards [25]. Parents' should be taught on ways to incorporate higher portions of vegetables and fruits in their children diet in order to increase their fiber intakes.

In the present study, more than half of the subjects had feeding problems $(60.8 \%)$, with a significantly higher incidence amongst the severe group. The severe group had a lower ability to control their feeding function muscles [26] that would lead to more feeding problems. There is a study that focusing only on swallowing, chewing and excessive drooling problems experienced among subjects from the Northern Ireland Cerebral Palsy Register (NICR). They found that subjects from GMFCS IV and V were at a higher risk of facing these feeding problems [27]. The presence of more than one type of feeding problems, food loss during meal times and food texture fed to subjects were the contributing risk factors to underweight incidence amongst cerebral palsy subjects. They further conclude that inadequate food intake due to presence of feeding problems faced by subjects were possible to affect cerebral palsy subjects' growth. Similar findings were also reported in the present study, whereby cerebral 
palsy subjects with feeding problems had significantly lower body mass index $(\mathrm{p}<0.05)$ and MUAC $(\mathrm{p}<0.001)[28]$.

The present study has several limitations. Firstly, due to the absence of local or national register for the cerebral palsy population in Malaysia, the random sampling method could not be conducted, which could cause biasness [7]. Besides, as the data collection focuses only at $\mathrm{CRC}$ and spastic centers, chances for the subjects with lower severity levels were not seen as these subjects were able to attend the school for the disabled children. Future studies should also include cerebral palsy subjects from schools, CRC and spastic centers in order to have a more representative sample. Parents were unable to report the types and dosage of certain supplementation prescribed by physician for their child. Therefore, the supplement intakes were not calculated as part of their nutrient intakes.

In conclusion, despite their satisfactory nutrient intake levels, the nutritional status amongst the severe cerebral palsy subjects were poorer compared to the mild group subjects. Feeding problems were associated with poorer nutritional status whereby swallowing and choking were significantly associated with subject's severity levels. Furthermore, presence of feeding problems amongst subjects significantly affects their nutritional status. Therefore, there is a need to plan specific nutritional intervention programs to improve the feeding problems and nutritional status of children and adolescent with cerebral palsy.

\section{ACKNOWLEDGEMENTS}

The researchers are grateful for the participation and cooperation of all the cerebral palsy children and adolescents, caretakers, teachers, Department of Social Welfare and health administrators of Community Rehabilitation Centre of Kuala Lumpur, Penang and Muar. Besides, we appreciate the involvement of all fieldworkers who helped directly or indirectly during the period of data collection.

\section{REFERENCES}

[1] Bax M, Goldstein M, Rosenbaum P, Leviton A, Paneth N, Dan B, Jacobsson B, Damiano

D. Proposed definition and classification of cerebral palsy, April 2005. Developmental Medicine and Child Neurology, 2005, 47(8):571-576 
[2] Stanley F. J., Blair E., Alberman E. Cerebral palsies: epidemiology and causal pathways. England: Cambridge University Press, 2000

[3] Day SM, Strauss DJ, Vachon PJ, Rosenbloom L, Shavelle RM, Wu YW. Growth patterns in a population of children and adolescents with cerebral palsy. Developmental Medicine and Child Neurology, 2007, 49(3):167-171

[4] Grammatikopoulou MG, Daskalou E, Tsigga M. Diet, feeding practices, and anthropometry of children and adolescents with cerebral palsy and their siblings. Nutrition, 2009, 25(6):620-626

[5] Sullivan PB, Lambert B, Rose M, Ford-Adams M, Johnson A, Griffiths P. Prevalence and severity of feeding and nutritional problems in children with neurological impairment: Oxford feeding study. Developmental Medicine and Child Neurology, 2000, 42(10):674-680

[6] Zainah SH, Ong LC, Sofiah A, Poh BK, Hussain IH. Determinants of linear growth in Malaysian children with cerebral palsy. Journal of Paediatrics and Child Health, 2001, 37(4):376-381

[7] Kuperminc MN, Gurka MJ, Bennis JA, Busby MG, Grossberg RI, Henderson RC, Stevenson R D. Anthropometric measures: Poor predictors of body fat in children with moderate to severe cerebral palsy. Developmental Medicine and Child Neurology, 2010, 52(9):824-830

[8] Krick J, Murphy-Miller P, Zeger S, Weight E. Pattern of growth in children with cerebral palsy. Journal of the American Dietetic Association, 1996, 96(7):680-685

[9] Fung EB, Samson-Fang L, Stallings VA, Conaway M, Liptak G, Henderson RC, Worley G, O’Donnell MA, Calvert R, Rosenbaum P, Chumlea W. Feeding dysfunction is associated with poor growth and health status in children with cerebral palsy. Journal of the American Dietetic Association, 2002, 102(3):361-373

[10]Marchand V, Motil KJ. Nutrition support for neurologically impaired children: A clinical report of the North American Society for Pediatric Gastroenterology, Hepatology, and Nutrition. Journal of Pediatric Gastroenterology and Nutrition, 2006, 43(1):123-135

[11]Calis EA, Veugelers R, Sheppard JJ, Tibboel D, Evenhuis HM, Penning C. Dysphagia in children with severe generalized cerebral palsy and intellectual disability. Developmental Medicine and Child Neurology, 2008, 50(8):625-630 
[12]Brooks J, Day S, Shavelle R, Strauss D. Low weight, morbidity, and mortality in children with cerebral palsy: New clinical growth charts. Pediatrics, 2011, 128(2):e299-307

[13]Palisano RJ, Rosenbaum P, Bartlett D, Livingston MH. Content validity of the expanded and revised Gross Motor Function Classification System. Developmental Medicine and Child Neurology, 2008, 50(10):744-750

[14]Tomoum HY, Badawy NB, Hassan NE, Alian KM. Anthropometry and body composition analysis in children with cerebral palsy. Clinical Nutrition, 2010, 29(4):477-481

[15] Stevenson RD. Use of segmental measures to estimate stature in children with cerebral palsy. Archives of Pediatrics and Adolescent Medicine, 1995, 149(6):658-662

[16]Frisancho AR. New norms of upper limb fat and muscle areas for assessment of nutritional status. American Journal of Clinical Nutrition, 1981, 34(11):2540-2545

[17]Schlenker J, Cocking J, Gilley J. Development of nutrition screening checklist for children with special needs. DC Paediatric Nutrition, 2003, 1(4):9-14

[18]Lucas B. L., Feucht S. A., Grieger L. Children with special health care needs: Nutrition care handbook. Chicago: American Dietetic Association, 2004

[19]National Coordinating Committee on Food and Nutrition (NCCFN). Recommended nutrient intakes for Malaysia. Putrajaya: Ministry of Health Malaysia, 2005

[20]Hurvitz EA, Green LB, Hornyak JE, Khurana SR, Koch LG. Body mass index measures in children with cerebral palsy related to gross motor function classification: A clinic-based study. American Journal of Physical Medicine and Rehabilitation, 2008, 87(5):395-403 [21]Day SM. Improving growth charts for children and adolescents with cerebral palsy through evidence-based clinical practice. Developmental Medicine and Child Neurology, 2010, 52(9):793

[22]Benfer KA, Weir KA, Bell KL, Ware RS, Davies PS, Boyd RN. Food and fluid texture consumption in a population-based cohort of preschool children with cerebral palsy: Relationship to dietary intake. Developmental Medicine and Child Neurology, 2015, 57(11):1056-1063

[23]Aggarwal S, Chadha R, Pathak R. Nutritional status and growth in children with cerebral palsy: A review. International Journal of Medical Science and Public Health, 2015, 4(6):737-744 
[24]Dannhauser A, Walsh C, Nel M. Nutritional status of disabled schoolchildren in Bloemfontein (2002-2003). South African Journal of Clinical Nutrition, 2007, 20(1):6-14

[25]Marciniak CM, Lee J, Jesselson M, Gaebler-Spira D. Cross-sectional study of bowel symptoms in adults with cerebral palsy: Prevalence and impact on quality of life. Archives of Physical Medicine and Rehabilitation, 2015, 96(12):2176-2183

[26]Herrera-Anaya E, Angarita-Fonseca A, Herrera-Galindo VM, Martínez-Marín RD, Rodríguez-Bayona CN. Association between gross motor function and nutritional status in children with cerebral palsy: A cross-sectional study from Colombia. Developmental Medicine and Child Neurology, 2016, 58(9):936-941

[27]Zhang JY, Oskoui M, Shevell M. A population-based study of communication impairment in cerebral palsy. Journal of Child Neurology, 2015, 30(3):277-284

[28]Perenc L, Przysada G, Trzeciak J. cerebral palsy in children as a risk factor for malnutrition. Annals of Nutrition and Metabolism, 2015, 66(4):224-232

\section{How to cite this article:}

Rajikan R, Zakaria N M, Manaf Z A, Yusoff N A M, Shahar S. The effect of feeding problems on the growth of children and adolescents with cerebral palsy. J. Fundam. Appl. Sci., 2017, $9(6 S), 787-804$. 